\title{
Cristina Azuela
}

\section{El penúltimo relato de las Cent Nouvelles nouvelles, ¿una "anti-Griselda" del siglo xv?"}

Este artículo surgió a partir del trabajo de Luciano Rossi, ${ }^{2}$ quien ha señalado que el orden de los relatos de Les Cens Nouvelles nouvelles dificre en los dos textos más antiguos que se conservan. En efecto, las dos últimas historias ocupan un orden invertido en el manuscrito de Glasgow y en la primera edición (de Vérard). ${ }^{3}$ Hasta las investigaciones de Rossi nadic había cuestionado el orden establecido por la edición, ya canónica, de Champion de $1928 .{ }^{4}$ Sin entrar en los detalles de las justas obscrvaciones de Rossi, parece que el último relato de esta edición de Champion, no es, en realidad, sino el penúltimo del texto original (desgraciadamente perdido), tal y

1 Una versión preliminar de este trabajo fue prescnlada cn las V Jomadas Mcdievales, que se llevaron a cabo en la Facultad de Filosofía y Lctras de la UNAM (México, septiembre de 1995).

2 V. Rossi ("David Auber..." y "Per il testn..."). Desgraciadamente, que yo sepa. cstos dos artículos no han recibido comentario alguno de los medievalistas.

${ }^{3}$ El manuscrito es el ms. 252 del Fondo Hunter de la Bibliotcca de la Universidad de Glasgow. La primera edición conservada es lá de Vérard. de 1492. Postcriormente aparecerán otras cdicioncs dc Vérard.

4 Picre Champion. Les Cent Nonvelles nouvelfes, Paris, Droz, 1928. Todas las ediciones modemas conservan este orden a pesar de que la primera cdición de 1492 mantiene el orden original del manuscrito perdido. La cdicion de Swectscr (Les Cenr). que aquí sc utiliza por ser mús accesible, retoma cl orden de Champion (v. sin embargo. las observaciones de Rossi ["David Aubert..."] con respecto a los crrorcs que Swectser introduce en su edición). 
como la edición de Vérard lo presenta. ${ }^{5}$ Lo anterior es particularmente interesante, ya que la nouvelle 99 es la última historia firmada por cl autor anónimo de la obra. ${ }^{6}$ Para Rossi, este relato constituye, en relación con la historia bocaciana de Griselda - también al final del Decamerón-, una especie de respuesta del autor francés, una "anti-Griselda", ? que propone una moralidad diferente de la del relato italiano. Sin embargo, al profundizar el examen de la nouvelle 99 nos encontramos no tanto con una moral distinta de la de Griselda, como con un cuestionamiento a la inclusión e interpretación de mensajes morales en la literatura. Además, la historia se presenta como una especie de compendio de las estrategias narrativas de la obra, donde dominan la sorpresa ${ }^{8}$ y los juegos con las espectativas del lector.

Pero valdría la pena comenzar con la compleja relación que la primera colección de nouvelles en lengua francesa guarda con el creador y representantc máximo del género, Boccaccio. ${ }^{9}$ Ya desde su título, las Cent Nouvelles nouvelles constituyen un brillante juego intertextual, donde, a la inevitable mención al modelo bocaciano, se añade no sólo el orgullo de la propia valía, sino una muestra del programa narrativo del autor. De hecho, el título de las Cien Nuevas Novelas, ${ }^{10}$ en su lengua original, Cent

5 En dos inventarios de la Biblialeca de los Duques de Borgoña, el de 1467 y el catálogo de 1487, Rossi encontró la descripción del manuscrito desaparecido, scgún la cual queda claro que el último rclato era la $\mathrm{n}$. 99 de la edición de Sweetser -y de Champion (v. Rossi, "Per il tcsto...", p. 402).

${ }^{6}$ En su mayoría, los relatos vienen encabezados por cl nombre de su narrador. En cl caso de la $\mathrm{n}$. 99 del manuscrito de Glasgow, cncontramos: La quatre vingrs XIXX nouvelle, par l'acteur. En cambio cn la cdición de Vérard no aparece mención alguna acerca del narrador del relato.

7 Rossi, "Per il testo...", p. 402 y, sobre todo, p. 412.

8 Pierre Dubuis (Les Cens...), csludioso de la nouvelle, definió la sorpresa final como uno de los rasgos constilulivos de la nouvelle borgoñona.

9 Con respecto a los estudios comparativos cntre el Decamerón y las Cens Nouvelles nouvelles, se pueden mencionar los de Toldo (Contributo...), Paris ("Ly nouvelle..."), Soderhjelm (La Nouvelle...), Dcsonay ("A propos..."), Sozzi (La Nouvelle...). Sticca (Boccuccio...) y Baker ("Narralive...").

10 También há sido traducido como Cien Cuentos Nuevos, nosotros mantene- 
Nouvelles nouvelles, recuerda de manera automática al famoso libro de las Cento Novelle (cien novelas), como cra conocido el Decamerón de Boccaccio en aquella época. ${ }^{11}$ Pero el escritor anónimo sabe distanciarse rápidamente de su modelo. En su breve dedicatoria al duque de Borgoña justifica su título precisando que si a las historias de Boccaccio, siendo ya antiguas, ${ }^{12}$ se les llama nuevas (nouvelles es tanto "nuevo", como "novela"), "se puede con razón fundada en la verdad aparente, intitular este libro Cent Nouvelles nouvelles..., ${ }^{13}$ ya que la tela, el cortc y la forma de ćstas, es de memoria bastante reciente; y de aspecto muy novedoso". ${ }^{14}$

Dc esta mancra cl autor no se limita a ser el primero en utilizar el término nouvelle para designar al género en lengua francesa, sino que define su importancia desde el punto de vista formal ${ }^{15}$ dando tanto relieve a la "novedad" de los relatos

mos el término "novela" en cl scntido de las Novelns ejemplases de Ccrvantes, es decir, rclato breve.

"Dubuis, Cenr..., p. 29. nota 2.

12 Hay que recordar que las Cent Nouvelles nonvelles (1462) sc cscriben más de un siglo después que el Decamerón (1351).

13 Literalmente "Cien nuevas nuevas", donde primero "nuevas" es adjetivo: "novedoso"; y después es sustantivo: "nueva", "noticia", "novcla"].

14 [Et pource que les cas descriptz et racomplez ou dit livres de Cent Nouvelles advindrent la pluspart es marches et meles d'Ytalic, ja long temps a. neantmains toutesfoiz, portant et retenant nom de Nouvcllcs, sc peut tresbicn et par raison fondéc en assez apparente vérité ce present livte intituler des Cent Nouvelles nouvelles, [...] aussi pourcc quc l'cstoffc, taille et fasson d'icelles est d'assez fresche memoire et de myne bcaucop nouvclle].

15 Hay que reconocer que en un principio el autor describe su obra como "petit oeuvre" [pequeña obra] cuyo estilo estaría muy lcjos de "altaindrc lc subtil et tresorné langage" [alcanzar la sutil y muy bicn aderczada lcngua] del Decamerón (Dedicatoria, l, 12, 16 y 13). Sin cmbargo csla profesion de humildad ante el maestro parcce bastanle convencional e incluso podría ser tópica en los prólogos a obras de nouvelles. Rossi, en su introducción al Novellieri dc Scrcambi, precisa que aunque los novelistas italianos, siguen el modelo bocaciano, no dudan en repudiar su estilo "troppo alto per un'opere comica" (p. XXII-XXIV). Así pues, para el autor francés no se trata simplemente de falta de oficio, como plantea Rasmussen cuando afirma que nuestro autor "habría descado imitar la noblcza 
narrados ("de memoria reciente"), como a la mancra de presentarlos, tambien innovadora (cl corte, la forma y el aspecto "muy novedoso").

Se ha dicho que el autor francés no utiliza a Boccaccio como modelo, sino como autoridad. Entre los relatos de ambos se puede hablar, más que de una relación directa, de semejanzas o, más bien, de coincidencia de motivos y paralelismos de la intriga, que en la mayor parte de los casos comparten también con algún fabliau. ${ }^{16}$ En el caso de las dos historias que nos ocupan, la distancia parccería bastante marcada.

Si iniciamos nuestro análisis con el relato de Boccaccio, lo primero que salta a la vista es que en un lapso de menos de cincuenta años esta novella en particular fue traducida al latín, al inglés, al francés, en verso, en prosá y en forma dramática, lo que muestra la enorme fascinación que la historia ejercería sobre la mentalidad medieval. ${ }^{17}$

del cstilo bocaciann pero sabbe bien que su talento no cs suficientc" (Rasmussen. La prose..., p. 176) ), sino de una clara conciencia cstilística.

${ }^{16} \mathrm{Se}$ han localizado solamente dos relatos de las Cent Nouvelles nouvelles que prescntan parccido ccrcano a los del Decamerón. Sin embargo, en ambos casos existen también fabliarox que podrian haber senvido como modelos. Los relatos son: Ia nouvelle 38, análoga a VII-8 y a VII-4, muy cercana de los fabliasex "de lá dame qui fit croirc à son mari qu' il rêvait", $y$ "des cheveux coupes": $y$ la nouvelle 78. que aunque pareceria ser la única que se relaciona directamentc con cl Decamerón por afinidades más obvias, cuenta iqualmente con un fabliau anólo. go: "Le chevalier qui fist sa femme confesser". Con respecto a las analogias entre las dos obras, v. el apéndice a la traducción al inglés de las Cent Nouvelles nouvelles de Robbins Rosscll (1960). pp. 381-390. aunque la mayor parte de las analogias entre el Decamerón y las Cent Nouvelles nouvelles que señala este crítico no son demasiado convincentes, sobre todo porque son vagas y nada prucba que no existan otras fucnics ( $v$, tambien Rey-flaud, la Farce: Dubuis, Les Cent Nouvelies; y Jodugne. "Considerations...").

${ }^{17}$ Petrarca traduce el relato de Boccaccio cn 1373. y produce una nueva versión un año despues. A finales de cse mismo siglo, estas dos variantes darán origen a diversas versiones en prosa, en verso, y hasta una obra dramśtica, todas en francés, además del "Cucnlo del clérigo" en los Cuentos de Canserburn' de Chaucer. Las reproducciones del texto sc multiplicarán durante los siglos siguientes, apareciendo cn numerosas compilacioncs, antologías y tratados didácticos. V. al respecto Golenisicheff-Koulouzoff ( $l$ 'Histoire...). 
La intriga, que narra los sufrimientos casi inhumanos que el marques de Sanluzzo hizo pasar a su esposa Griselda para probar su sumisión y su constancia en el matrimonio, es bien conocida. Habiéndose casado con ella a pesar de su origen humilde, el marqués le arrancará, poco después de nacer, los dos hijos, fingiendo darles muerte. Griselda acata las decisiones de su marido sin quejarse, dcmostrándole así la docilidad incondicional que le prometiera al accptar ser su esposa. Más tarde, el marqués fingirá descos de volver a casarse, for $z a n d o$ a Griselda a abandonar el domicilio conyugal, despojada incluso de sus ropajes. La requicre, sin embargo, para ocuparse de los preparativos de la boda. Griselda, esta vez también sc conforma sin reparos a las resoluciones de su marido, llegando incluso a alabar a la novia (que no es en realidad, sino su propia hija). Al final, el marqués, satisfecho por la devoción de su mujer, le devuelve a sus hijos y le restituye el lugar que lc coresponde a su lado.

Ya Petrarca, al traducir al latín la historia, añade un comentario donde precisa:

\begin{abstract}
Al narrar esta historia [...] no he tenido intención alguna de invitar a las damas de nuestra época a imitar la paciencia de csta esposa que me parece casi inimitable; he querido solamente inspirar a mis lectoras a imitar al menos la firmeza de una mujer, teniendo la fuerza de conducirsc con Dios de la misma manera en que ella se condujo con su marido... (Petrarca. Griseldis, p. 65). ${ }^{18}$
\end{abstract}

Este comentario scrá retomado en las vcrsiones francesas, ${ }^{19}$ donde siempre se afima:

18 Todas las Iraducciones al españul son mias.

19 Algo semejante sucede en el "Cuento del Clérigo" de los Cuentos de Canterbury, donde Chauecr recoma la versión de Petrarca. Aquil. cl clérigo que narra el relato de Grisclda no pucde evitar la ironía al subrayar la imposibilidad de una sumisión conyugal parccida. 
Y como parccería imposible que actualmente las damas casadas puedan seguir al pie de la letra las grandes virtudes de dicha marquesa... (Prologue du, li. 54-57). ${ }^{20}$

Es con respecto a la posibilidad o imposibilidad de emular a la virtuosa Griselda como podemos comenzar a examinar la relación de esta historia con la de las Cent Nouvelles nouvelles. Rossi ha señalado que esta última obra se cierra, según las normas retóricas en vigor y siguiendo el modelo del Decamerón, con un relato de corte aleccionador, que exalta la entereza femenina. Al igual que Boccaccio, el francés habría inaugurado su texto con una historia de adulterio, para concluirlo con una escena de virtud conyugal. ${ }^{21}$ Sólo que esta última, según Rossi, contrasta con el espíritu fcudal de la novella bocaciana por la factura inédita y modema, es decir, burguesa, de su moral (Rossi, "Per il testo...", p. 402). Sin embargo, en Les Cent Nouvelles nouvelles parece succder algo más:

A diferencia de la crueldad del marqués de Sanluzzo, el autor francés nos presenta un marido comprensivo y sabio que, conociendo las debilidades femeninas y consciente de la juventud de su mujer, no intenta en absoluto apartarla de las inclinaciones naturales de su sexo y de su edad, sino que la aconseja sobre la mejor manera de satisfaccrlas sin provocar un escándalo. Antes de salir de viaje no le propone a su esposa que le sea fiel, sino que elija un amante entre los gentileshombres más

${ }^{20}$ [Ec combien qu'il sambleroit impossible au jourd'uy que les dames mariécs peussent ensuir à la letıre les grans vertus de la dicte marquise... I

21 Rossi parece partir aquí de la interpretación de Branca, quien vio en el Decamerón un orden preestablecido que va de la reprobación de todos los vicios - en la primera novela, la de Ciappelletto - hasta la exaltación absoluta de la virfud en la historia de la paciente Griselda (Branca, Hoccaccio..., p. 31I). Para Branca resulta realmente muy significativo que después de haber recorrido todos los tipos de comportamiento humano en lás nucve primeras jornadas, Boccaccio consagre la última a rclatos serios que ilustran la gencrosidad. Es así como cierra la obra con historias ejemplares que ejercen un contrapeso al mue strario de vicios y engaños de los relatos precedentes. Sin cmbargo, como se discutirá más adclantc, cl mensaje cdificantc de Griselda resulta bastante problemático. 
prudentes y sabios que conozca. Si la esposa parece de entrada horrorizada por la proposición de su marido, no tardará, sin embargo, en corroborar la justeza de sus predicciones. Movida, en efecto, por la fucrza dc su "natural inclinación", pero obediente siempre a los consejos recibidos, buscará un amante que responda a las condiciones emitidas por el esposo.

Parecería evidente que al pedirle que tomara como amantc a un hombre sabio, en cierto modo el marido había anulado la posibilidad del adulterio. De hecho, ningún sabio se permitiría cometer tal acto. Y en nuestra historia eso es lo que sucede: e] clegido emplea una artimaña para eludir la aventura. Es así como el último relato de las Cent Nouvelles nouvelles, podía erigirse en un ejemplo moral que proclamaba no sólo el triunfo de la castidad, sino también las virtudes de la tolerancia, al tiempo que respondía a la historia de Boccaccio con una historia más del gusto del público borgoñón, menos rebuscada, más ligera. Hasta aquí los argumentos de Rossi.

Si se toma en cuenta la tendencia de nuestro autor a retomar historias conocidas dándoles un giro inesperado, o reutilizándolas con fines irónicos que las renucvan totalmente, se puede aceptar de entrada la lectura que Rossi realiza del relato como una "anti-Grisclda". Y sin embargo, a mi modo de ver el escritor borgoñón no se contenta con esto. Frentc al ejemplo de virtud que ofrece Boccaccio, al francés no parece interesarle tanto oponerle una virtud más humana, sino cuestionar los principios mismos de esa virtud. De hecho, si bien es cierto que la dama de su relato termina por ser casta, no lo ha sido por voluntad propia, sino por obra de otros -el "amante", y en último caso, su marido-.

En efecto, cuando la dama finalmente se declara vencida y, eligiendo a un joven clérigo, le revela su amor, éste se confiesa halagado, pero le pide una pequeña demora. Se encuentra cumplicndo un voto de abstinencia del que le restan sólo dos meses, pero si la dama acepta colaborar, podrían completarlo entre 
los dos al cabo de un mes de ayuno. Habiendo accptado, la dama se encontrará progresivamente debilitada por ese mes de privaciones. Desde el principio, su "calor natural comenzó a enfriarse considerablemente" (n. 99, li. 699-700) pero no será sino al ténnino del plazo, cuando se dará cuenta de que "el deseo no le parecía ya tanto como había sido antes" (ibid., li. 725). Es entonces cuando la dama comprende las intenciones del clérigo de apartarle del pecado, y se lo agradece.

La historia termina, pues, con la perfecta castidad de la dama. Pero tal vez sería útil recordar aquí que las versiones francesas de la historia de Griselda no dejaban de subrayar que la marquesa "se venció a sí misma y quedó victoriosa" (Prologue du, li. 50-5I). Lo notable, como se explicaba en estos textos, residía en el esfuerzo de voluntad sobre sí:

venciéndose y sobrcponiéndose a sí misma, forzando la naturaleza, lo que es cosa de mayor mérito que vencer a otro [...] Vencer [...] es la fuerza de los caballeros, pero vencerse a sí mismo es la fuerza de la virtud misma (Prologue du, li. 40-46).

En cambio, si en la nouvelle franccsa la dama pudo vencer sus deseos, no fue sino mediante el ayuno como probó su fuerza de voluntad. ${ }^{22} \mathrm{Y}$, paradójicamente, este triunfo sobre sí misma ${ }^{23}$ tenía como objetivo la satisfacción de descos aún más sensuales que los de la comida. Si la joven efectivamente logró dominar sus apetitos, fue porque se encontraba aguijoneada por otros

${ }^{22}$ Y juslamente aqui contrasta la solidez de Griselda conira la falla de control de esta joven, que a fin de cuentas no logra cumplir casi nada de lo que se propone: primero jura que sicmpre querrá ser fiel, y no larda en darse cucata de que no es así: lucgo trata de ser infiel, sólo para comprobar que tampoco lo puede llevar a cabo. Obviamentc cl autor francés parte de una imagen bastante más desvalorizada de la mujer.

${ }^{23}$ Los términos en que se habla de csta "victoria sobre sí misma" son justamente los de las versiones francesas de Grisclda: para animar a la dama a continuar cl ayuno el clérigo le dicc: "Dad prucba de consiancia y firmeza... si vuestra naturaicza cs débil dominadla con rigor y fuerza de carácter". 
más apremiantes. Así, aunque indudablemente la virtud triunfó, se trata de un triunfo por las razones equivocadas.

Juicios como el de Rossi, que consideran el peso edificante de la historia. ${ }^{24}$ no excluyen de ninguna manera una lectura irónica sustentada en el hecho de que la moralcja de la historia es conflictiva, pues la castidad no triunfa por los buenos motivos. Se trata, así, de una moralcja incierta, que, desde nuestro punto de vista, cuestiona incluso el hecho de que haya una moraleja.

De hecho, cn este relato, los mensajes morales se manejan de forma contradictoria: el marido se preocupa por la debilidad do su mujer durante su ausencia, pero no tanto por su posible falta de honestidad o de castidad, como porque nadie se percate de ello. El relato no gira cn tomo a la demostración de la virtud, sino al ocultamiento del vicio. Es "cuidar las apariencias" lo que cuenta, y no el comportamiento real; y aunque éste termine por ser virtuoso, casi lo cs por añadidura y no por haber constituido el objetivo... Sin embargo, el autor de las Cent Nouvelles nouvelles no está innovando nada al presentar tal ambigüedad en su mensaje. A pesar de que con el relato de Griselda, Boccaccio parecía dar un final edificante al Decamerón, no debemos olvidar que al concluir su historia, Dioneo —l narrador- no puedc cvitar añadir su opinión, con frases que clausuran, además, todas las narraciones de la obra:

[...] ¿y quién, además de Griselda, hubiera podido sufrir no sólo con tranquilidad, sino con alegría las pruebas rigurosas e increíbles a las que Gualterio la sometió? En cuanto a éstc, bien se habría merecido una mujer que. despedida en camisa de su

24 Y no es el único. Gustave Cohen, despucs de comentarla. concluye "Se advicre aqul que la levadura de la fe persistc en lo hondo de las almas" (\$a vida, p. 292). Pero también Gocthc. en 1795. había retomado esta historia justamenec por su contenido cjemplar (צ. Rossi. "Per il testo...' pp. 412-413). Para una historia de cste relato. desde su primcra version cn latín, hasta Goethe. v. Pabst, la novela corra..., p. 314. nola 18. 
casa, hubicra sabido hacerse sacudir el vello púbico y obtener con sus encantos un rico vestido de algún otro (X-10, par. 69).

Es con la chabacancria misma de su expresión con lo que el narrador parecería tratar de desmantelar el contenido ejemplar del relato, cerrando el Decamerón, como lo pone un crítico, con "una humorada que revela un enigma no resuclto" (CazaléBerard, “Jcux...", p. 59). Y en efecto, la historia en sí resulta problemática para su interpretación. Es difícil entender la crueldad del marqués y la docilidad de su esposa; parcce desproporcionado el castigo para probar lo que desde el inicio estaba casi probado al describir, al comienzo, las virtudes de Griselda, pero las frases finales de Dioneo vuelven más complicado aún el desciframicnto del mensaje: “[...]¿Gualterio está loco o es un sabio? ¿El destino de Griselda consagra el triunfo de la mujer, o su alienación?" se pregunta Cazalé-Berard ("Jeux...", p. 59).

La ambigüedad de este final no sólo matiza la conclusión del relato, sino que impide una interpretación unívoca tanto de la historia como de la obra en gencral. ${ }^{25}$ Así, aunque quisiéramos ver un modelo de sumisión conyugal en la narración, estaríamos traicionando a Boccaccio si olvidáramos que a lo largo de todo el Decamerón no ha dejado de proponcr una moral humanista fundada sobre una ética secular donde la razón y el amor valen más que cualquier convención tradicional. ${ }^{26}$

En otro lugar he examinado el cuestionamiento a la vocación edificante de la literatura que realizan autores de nouvelle como Boccaccio y el borgoñón (Azuela, “Edificación..."). Pareccría que al teñir de ambigüedad los textos conclusivos de sus obras,

25 Con respeclo de esla ambigücdad final, Kirkpatrick la compara con la versión de Pclrarca, quicn sí había dado a su rclalo una "dirección moral definitiva" (pp. 233-234).

${ }^{26}$ Boccaccio es precursor de una nueva sabiduría fundada en la comprensión de los valores humanos, que se basa no en los dogmas religiosos, sino en una norma ética autónoma (Sticca, "Boccaccio...", pp. 231-232). 
estos escritores quisicran soslayar la obligación de edificar que existía como presupuesto de la actividad literaria. Hay, en ambos autores, una actitud burlona que se rebela, de manera patente, contra la tradición ejemplar del género. Varios relatos de las Cent Nouvelles nouvelles carecen de mensaje moral explícito, y aunque algunos revelan juicios del autor donde se asientan todas las convenciones de una moral tradicional, ${ }^{27}$ en muchos otros no sólo se niega a dar sus opiniones, sino quc se esfuerza - como Boccaccio en repetidos casos, adcmás del de Grisel$\mathrm{da}-{ }^{28}$ en obstaculizar cualquicr intento de sacar una moraleja en claro. Es así como el francés puede insertar al final de su obra una historia que, con la apariencia de transmitir un mensaje edificante, impugna todo intento de buscar la enseñanza, al situarla en una perspectiva sospechosa.

La enseñanza que se podría obtener así (en caso de que la hubiera), parecería dcscalificarse a sí misma. Si la castidad es lo que importa, como parece al final, entonces toda la primera parte de la historia carece de sentido; si la castidad no importa, como lo sugiere el marido, entonces el final de la historia es una trampa; y finalmente, aun cuando el mensaje fuera que la castidad debe triunfar por encima de las malas intenciones, entonces el autor estaría haciendo, a la vez, un serio cuestionamiento en tomo a la duplicidad del lenguaje; a la disgregación entre lo que se dice y lo que se piensa; entre las palabras y las intenciones; y a las diversas interpretaciones a que todo cllo da pie. De hecho éstos parecen ser temas que le preocupan. ${ }^{29}$

${ }^{27}$ Como lo afirma Jeay, quien sostiene que la obra en su conjunto deja ver una moral implícita que es imposible negar (Jeay, "L'enchassement...". pp. 200-201). Sin embargo, en mi análisis es claro también cierto rechazo a la intención edificadora de los relatos análisis (Azucla “Edificación..."): v. por ejemplo, la conclusión irónica de varias nouvelles, que parece hacer mofa del uso de proverbios moralizadores para cerrar las historias: nouvelles 19, 30, 55, 79 y cambién 31,40 . 76. 80...). Esto (ambién sucede en el Decamerón. v. nola siguiente.

${ }^{28}$ V. los relatos II-7, III-3. II-4, 11I-10, V-10 y también I-1, V.8, VII-1 y VII-4.

29 Como a muchos escritores del final del Medievo, incluycndo de nuevo a Boccaccio. El tcma de la discontinuidad cntrc lo que se piensa y lo que se dice en 
Será, por ejemplo, muy divertido observar cómo el marido imita el discurso de las damas que hipocritamente tratan de evitar las sospechas de sus esposos burlados. Pocas líneas más abajo constatará que su propia mujer no puede cvitar el cmplco de las mismas formulas en una protesta que no hubiera podido ser más sincera. Refiriéndose a las hipócritas que prometen fidelidad a sus maridos, el comerciante había dicho:

Conozco sus respuestas y cuáles son las palabras que saben usar [y añadió, imitándolas:] Dios no quiera jamás que yo os haga tales promesas. A él le pido que permita que la tierra se abra y me irague y devore viva, el día y la hora en que, no digo lo cometa, sino que tenga una sola y ligera idea de cometerlo [el adulterio]. ${ }^{30}$

Por su lado, la esposa arguye con la mayor franqueza:

Le pido muy humildementc a Dios, y con las manos juntas le suplico que haga y ordene que un abismo se abra donde yo sea arrojada con los miembros arrancados y atormentada por muerte cruel, si jamás llegara el día en que yo debiera, no digo cometer deslealtad a nuestro matrimonio, sino simplemente tener la más breve idea de cometerla. ${ }^{31}$

La repetición de las mismas palabras para discursos que deberían más bien revelar su diferencia radical, parccería dejar surgir furtivamente una sospecha al respecto de ese lenguaje

los Cuensos de Canierbuny de Chaucer y en el Decameron de Boccaccio ha sido examinado por Beekman Taylor ("Peynted Confessiouns...").

${ }^{30}$ |Je sçay leurs responses el de quelz molz sq̧event user: [...] 'He! mon mary, [...] ja Dicu ne veille que je vous face telles promesses. a qui je prie qu'il permette la terre ouvrir qu me englotisse el devore loule vive, au jour cl heure que je n"y pas commcturay, mais auray unc scule el legiere penséc a la commcltre ...'].

31 [Je requier treshumblement a Dicu el a joinctes mains luy prie qu'il face ct commendc ung abysme ouvrir ou je soye jecléc. les membres tous erachez. et pourmentec de mort crucllc, si jamais le jour vient ou je doye non seullement commectre desloyauté en nostre mariage. mais sans plus en avoir une breve penséc de le coinmetire] (n. 99, li. 349-355). 
cuyos signos, retomados en el espacio de una misma página, adquicren resonancias ultrajantes y virtuosas sin que realmente sea posible distinguir una de la otra.

El lenguaje aparece, pues, como no muy digno de confianza. En una gran mayoría de los distintos relatos de la obra - y en esto también coincide el borgoñón con Boccacccio-, cl autor nos ha ofrecido todo un abanico de engaños perpetrados gracias a la habilidad de manipulación del lenguaje. Lenguaje doble que se erige en el instrumento indispensable para la satisfacción de alguna pasión mundana, si no es lá simple mezquindad o cl antojo de burlar al otro. Y aquí cabría preguntarse por qué habriamos de confiar en una moraleja expresada con ese mismo lenguaje... ${ }^{32}$

Por otra parte, a lo largo de toda su obra, nuestro autor -al igual que Boccaccio- se ha complacido reiteradamente en demostrar que sc pueden encontrar distintas significaciones $\mathrm{e}$ intcrpretaciones para un mismo hecho. En efecto, cada vez que un personaje engaña a otro tiene lugar una multiplicidad de interpretaciones, ya que mientras para la víctima ciertas palabras o cierta situación significan una cosa, para el que se burla de ella significan lo contrario. Y csto se repite una y otra vez. ${ }^{33}$

32 Hay, en efecto, en las nouvelles, un cuestionamiento del valor mismo de la palabra. que pone de relicve la insoslayable ambiguedad del lenguaje (Azuela. "L'activite...).

${ }^{33} \mathrm{La}$ insistencia sobre la reproducción de situaciones de comunicacion que sc da en las nouvelles (v. Azucla. "L'activité..."). parcce subrayar, justamente, la complcjidad del fenómeno dc la reccpción y de la interpretación de lo que se oyc. En vanas historias Boccaccio desplicga una multiplicidad dc reccptores diversos que darán al mismo hecho intcrprelaciones distintas. Asf, ante la confesión hipócrita de Ciappelletto, tras el ingenuo confesor que le crec todo, aparecen los usurcros que saben que se trata de una farsa (I-1. Algo similar succde en VI-10. Cf. Marcus. An Allegory..., y Mazzola. "The Decamcron..."). Otros rclatos ofrecen siluaciones donde la misma frase debe scr simultáneamente interpretada de mancras diversas, como en cl caso del rezo para cspantar fintasmas que una esposa pide al marido que diga. con la intención de que su amantc, que cspera al otro lado de la puerta, comprenda que debe partir de inmediato (VII-I). En las Cent Nouvelles nouvelles tencmos varios ejemplos donde una frasc es interpretada de 
Parecería que, ante la diversidad de reacciones posibles, nuestro autor quisiera advertirnos también contra las interpretaciones rígidas. ${ }^{34} \mathrm{El}$ primer encuentro del clérigo y la dama -cuando al fin ella logra hacerlo venir a su casa - constituye una muestra de esto: frente a una misma situación, ambos reaccionan de maneras distintas:

cada uno esperaba las palabras de su compañero, él de una forma, ella de otra, pues el clérigo pensaba que ella le revelaria algún asunto importante y difícil, y quería dejarla comenzar, y clla, por su parte, pensando que él era lan sabio que sin declararle ni mostrarle más, podría entender la razón por la que lo había llamado $[\ldots]^{35}$

Parecería incluso que aquellos detalles que hubieran debido ofrecer cvidencia de la naturaleza de la invitación de la dama, se hubieran vaciado de sentido para el clérigo, como si de pronto todas las fórmulas y los gestos corteses se hubieran tornado inoperantes. ${ }^{36}$

Esta divergencia de perspectivas para descodificar una situación cuyas señales, se suponía, eran univocas y explícitas,

manera distinta por diversos personajes (por ejemplo, nouvelles $3,28,32,34,41$, 44 y también nouvelles 20,39 . En la nouvelle 94 se escenifican las dificultades de la comunicación cuando un cura decide interpretar a su manera las órdencs de sus supcriores; v. lambién nouvelle 5).

${ }^{34}$ Como Markus lo pone, en relación con el Decamerón "Wc must not believe that our intcrpretation of the narrative is in any sense final, and always allow for altemative, less obvious cxplanation" (Markus 1979, p. 22; v. también Mazzora 1972, p. 35).

35 [chascun actendoit la parolle de son compaignon, l'un en unc maniere, l'autrc en l'autre; car le clerc cuidoit que elle luy deust ouvrir quclque matiere grosse et difficile, et la vouloit laisser commencer; et elle, d'aultre cosic, pensant qu'il fust si sage, que sans luy declarer ne monstrer plus avant, il deust cntendre pour qouy clle l'avoit mandé] (n. 99. li. 554-560).

${ }^{36}$ De hecho a partir del momento en que ella decidc involucrarse en una aventura amorosa con el clérigo, los métodos tt́picos para cste tipo de situación dcjan de funcionar: a pesar de que su elegido pasaba diariamente frente a su casa, nunca volteará la cara para verla; $3 s i$, todos los adornos y arreglos que ella se pone para llamar su atención resultan inútilcs, y su belleza pasa desapcrcibida. 
nos lleva a la descodificación de los relatos, que también pueden ser objeto de lecturas contradictorias.

Finalmente, el hecho de que la excusa del ayuno no sea percibida —incluso por el lector - ${ }^{37}$ como una mentira, refuerza esta especic de advertencia. La cual continúa durante la descripción de los esfuerzos de la joven, quien a pesar de su debilitamiento físico, persevera cumpliendo su promesa. Ella actúa siempre con la pcrspectiva de su aventura amorosa, aún cuando todo lo que hace no tiene como fin, a los ojos del clérigo, sino apartarla del adulterio.

Aquí se presenta nuevamente la divcrgencia entre dos interpretaciones del mismo hecho, lo que, como descodificadores del significado último del relato, nos pone en guardia. Así, frente a la obligación tradicional de acreditar la literatura por su capacidad cdificante, el autor enfatiza la posibilidad de realizar diferentes lecturas de un hecho -o de un relato-, como alertando a su lector a abrirse a explicaciones alternativas diversas.

Por ello se puede afirmar que esta narración que cierra las Cent Nouvelles nouvelles adquiere toda su importancia no como clausura moralista de la obra, que respondería a la Griselda de Boccaccio, sino como irónica protesta ante la imposición de aportar un mensaje al lector, al tiempo que, sin dejar de jugar con las expectativas de ese lector, le ofrece un resumen de las estrategias narrativas que han marcado todos sus relatos.

Lo antcrior se hace aún más evidente con la amplificación de una de las tendencias del autor: la de introducir el texto con un tono elevado que alienta ciertas espectativas para después frustrarlas, toda vez que, casi sin transición, baja el tono dando lugar a un relato más bien pícaro (Sozzi, La Nouvelle..., pp. $80-81$ y 348 ).

${ }^{37}$ Aunque el lector de aquella epoca hicicra automáticamente la relación entre ayuno y abstinencia sexual, el tipo de historia que parece iniciarse se presta a que el lecior cspere cualquier tipo de enredo a partir de la cxcusa del clérigo. 
En efecto, la primera parte de esta historia, aparentemente ejemplar, ${ }^{38}$ expone con tono serio, y durante varias páginas, el deseo del comerciante de formar un linaje, por lo que termina desposando a la joven protagonista del relato. Esta preocupación será muy pronto abandonada, e inexplicablemente nunca se volverá a mencionar el asunto. Se trata en realidad de la primera de las expcctativas frustradas del lector.

La segunda proviene de la decisión del mercader, en tono ya más ligero, de efectuar un viaje sin preocuparse por la fidelidad de su mujer. Y aquí, dado el contenido de la mayor parte de las historias de la obra, el lector puede, sin duda, regocijarse ante el giro novedoso de esta intriga que, ofreciendo todos los elementos de una narración atrevida (esposa joven y bella, marido viejo y ausente, desasosiegos por el honor...), consigue aportar una variación insólita al modelo tradicional de relato de triángulo amoroso. El texto aporta, por su novedosa perspectiva, uno de los diálogos entre esposos más originales de la obra: el marido no pide fidelidad sino que aconseja a la inexperta esposa cómo lograr una aventura extramarital sin escándalos; ella, por su parte -como ya se ha señalado- se espanta ante la falta de decoro de tales proposiciones.

La última de las espectativas frustradas del lector aparecerá cuando la joven se declare, por fin, necesitada de amor. Hemos visto cómo concluyen sus intentos de infidelidad.

El lector puede, en el momento postrero del relato, recapitular sus detalles sorprendentcs: primero ur deseo de "formar linaje" que no tiene seguimiento; después un marido que no se habría molestado por la infidelidad de su mujer, y finalmente, un amante que se rehúsa a cometer el adulterio (cl único adulterio de la obra, por cierto, que no hubiera representado una traición a la lealtad debida al marido). Del mismo modo se

38 Se ha dicho incluso que tiene aspecto de exemplum latino (Mermier, "A propos...", p. 150). 
pucden notar los cambios de registro: se trata de una narración con apariencia edificante al principio, que parece transformarse en una historia de picardía, para terminar con una moraleja sospechosa, que toma imposible el intento de definir el todo con certeza.

Vemos, pues, que el narrador cierra de manera brillante su obra al efectuar una última inversión a las expectativas del receptor, cosa que parecía constituir su objetivo principal desde el inicio: en efecto, la infidelidad que el narratario espcraba tuvo lugar, pero en relación a sus propias previsiones acerca del relato. De esta manera, y de forma muy aparente, podemos ver que en las nouvelles, no se trata únicamente de maridos engañados, sino también de lectores burlados.

Guy Mermier había ya sugerido que esta historia representa una beffa $a^{39}$ cuya víctima es el propio lector. Sin embargo, habría que añadir que esto no es simplemente, como Mermier afirma, porque "el lector se deja ir con las apariencias y espera un desenlace erótico" (Mermier, "À propos...", p. 149), sino porque la inversión de los elementos tradicionales de las historias de triángulo amoroso realiza aquí un trastocamiento de todos los procedimientos a los que el lector estaba habituado, sin abandonar, a pesar de todo, la sorpresa final (sorpresa que se duplica al vislumbrarse el cuestionamento simultáneo a su apariencia edificante).

Así, por ejemplo, si, como hcmos mencionado, el lenguaje ha servido en todos los relatos para burlar o aprovecharse de alguien, en esta historia el engaño del lenguaje no conduce a ninguna bajeza, sino, por el contrario, a la exaltación de la castidad. Nuevamente, la originalidad de la perspectiva sorprende: el único que engaña es el personaje virtuoso. Los que lo son

39 Las beffe son relatos de timos y engaños. de burladores y burlados, que abundan entre las nouvelles. Se ha llegado a decir que estas historias, junto con los morti -relatos de respuestas ingeniosas-. son las que constituyen propiamente al géncro de la nouvelle (Wetzel, "Eléments..." ). 
menos resultan más sinceros que aquél. Justo aquellos que no se preocupan por la castidad o el pecado son quienes critican el lenguaje hipocrita de las mujeres pecadoras y adúlteras, mientras que el único que procura la virtud es quien usa efectivamentc el lenguaje hipócrita. ${ }^{40}$

La nouvelle 99 representa, así, un ejemplo magistral de "rcutilización" del material convencional de manera innovadora, lo que parece haber constituido - si atendemos a su dedicatoria- uno de los objetivos de su autor. El relato representa también una especie de resumen de las técnicas narrativas de toda la obra, entre las cuales los cambios de estilo y tono, y la sorpresa final, ocupan el lugar privilegiado.

Volviendo a la Griselda del Decamerón - que era el punto de partida de este trabajo_, podemos retomar la tesis de Rossi pero modificando y amplificando sus conclusiones: si en efecto el autor francés quiso responder a Boccaccio con un relato más del gusto de su público, no se contentó simplemente con dudar de la exaltación ciega de la virtud de Griselda, sino que cuestionó el hecho mismo de que se incluyera un mensaje edificantc en las nouvelles. Tal vez vio perfectamente la ambigủedad que tiñe el final de la historia bocaciana, y trato, por su parte, de detonar esa ambigúedad aportando un relato moral cuya moralidad no era del todo transparente.

Existía, ciertamente, una consigna de edificación para los relatos breves. ${ }^{41}$ La estrategia del autor francés es poner en escena la diversidad de reacciones interpretativas que un mismo hecho provoca, para insinuar su resistencia a las interpretaciones univocas de las narraciones.

Podríamos concluir que la notable ausencia de voluntad moralizadora del libro borgoñón se refuerza con la inserción de este relato como cierre de la obra. Sin embargo, no hay que ol-

to En Boccaccio, por otro lado, es Gualterio, quien, para probar la virtud de Griselda, hace el mal, miente, inflige castigos innecesarios..

41 V. Pabst, La novela corla.. 
vidar que fue un lector del siglo xv quien decidió cambiar la ubicación de esta historia, para que el relato que cerrara la obra fuera el del cura que comió perdices en tiempos de ayuno.

No es fácil dilucidar los motivos de este cambio en el orden de las nouvelles. ${ }^{42}$ Pero no se puede excluir la imagen de un copista que, sensible al tono general de la obra, hubiera cncontrado mejor situada, para concluirla, una narración que parece proponerle al lector una reflexión distinta acerca de la obra, en vez de ofrecerle una meditación edificante -que, para colmo, resulta ser de una moralidad bastante incierta-. En cfecto, la nouvelle de las perdices termina con una risa generalizada provocada por la pretensión del obispo de haber transmutado las perdices en pescados para no romper el ayuno al comerlas:

[Todos] comenzaron a reir e hicieron como si creyeran la mentira de su patrón, que resultaba tan ingeniosa y bien aderezada. Desde entonces siempre lo apreciaron, y la contaron alegremente aquí y alla..$^{43}$

Parecería que con esto se nos pidiera no tomar tan en serio los. relatos de la obra. En vez de moralizar, hay que admirar el arte del narrador, cuyas nouvelles deben resultar, como la broma del obispo, "ingeniosas y bien aderezadas" para que cualquiera pueda volver a contarlas...

$\$ 2$ Rossi propone que la razón podría residir en el hecho de que lá copia de Glasgow cstuviera ligada de alguna forma con Philippe de Loan. Asi, cl traslado del relato de las perdices al final, y su atribucion al propio Philippe de Loan, podran sugerir que este personaje habria sido el autor de la obra completa. Esta hipólesis se reforzaría porque esła atribución a Loan no aparece en la edición de Verard, y que, siendo de una mano diferentc, podría haber sido insertada en un momento posterior a la compilación de la obra (v. Rossi, "Per il testo...", pp. 402. 403. y cambién Champion, Les Cents... pp. Lv y cxvı).

43 [Tous] [commencerent a rirc, ct firent scmblant de adjouster foy a la bourdc de Icur maistre, trop subtillement fardce et coullource: et en tindrent depuis manicre du bien de luy et aussi maintesfois en divers licux joyeusement [1a] racompterent] (n. 100, li. 104-109). 


\section{Bibliografía}

Azufı.A, María Cristina, "L'activité orale dans la nouvelle médiévale: Les Cent nouvelles nouvelles, Le Décaméron et les Camerbury Tales", Romania, 115 (3-4), 1997, pp. 519-535.

_. "¿Edificación en la nouvelle medieval?", Medievalia (en prensa).

BAKER, Mary, "Narrative strategy in the novella: The Decameron and the Cent Nouvelle nouvelle", en Forum Italicum, vol. 18-2. 1984. pp. 230-239.

Bekkman, Taylor Paul. "Peynted Confessiouns: Boccaccio \& Chaucer", Comparative Literature, 34 (1982), pp. 116-129.

Boccaccio, Giovanni, Decameron. Vittore Branca (ed.), Milano: Mondadori Editore, 1985.

Branca, Vitore, Boccaccio Medievale e Nouvi Studi sul Decameron. Florencia: G. C. Sansoni, 1986.

- Boccaccio. The Man and His Works, tr. al inglés por Richard Monges. N. York: The Harvest Press, N. York University, 1976.

CazaLE-Berard, Claude, "Jeux de masques. Fonctions nartatives et thématiques dans le Decameron", Revue des études iroliennes núm. 14, 1987, pp. 32-59.

Cent Nouvelles nouvelles (Les), ed. crítica de Franklin P. Sweetser. Génova: Droz, 1966.

— (trad. al francés moderno de Pierre Dubois), Lyon: Presses Universitaires de Lyon, 1991.

Champion. Pierre. Les Cent Nouvelles nouvelles, Paris: Droz, 1928.

Cohen, Gustave, La Vida Literaria en la Edad Media México: FCE, 1958, 12a reimpr. 1981).

Desoray, F., "A propos d'une nouvelle édition des Cent Nouvelle nouvelle". en Revue Belge de Philologie et d'Histoire, vol. 8-3, 1929. pp. 993-1027.

Dubus, Roger, Les Cent Nouvelles nouvelles et la tradition de la nouvelle en France au Moyen Age, Grenoble: Presses Universitaires de Grenoble, 1973.

GolenistcherF-Koutouzofr, Elie, L'Histoire de Griseldis en France au XIVé siécle. París: Droz, 1933. 
Jear, Madeleinc. "L'enchàssement narratif: un jeu de masques, L'exemple des Cen Nouvelles nouvelles", en Marie-Louise Ollier (cd.). Masques ę déguisements dans la littérature médiévale. Montreal: Presses de l'Université de Montréal, 1988, pp. 193-201. Jodave, Omer, "Considéralions sur le fabliau", en Mélanges offerts à René Crozet. Poiticrs: Sociéte d'Etudes Médiévales, 1966. pp. 1043-55.

KIRKPatrick, Robin. "The Grisclda Story in Boccaccio, Petrarch and Chaucer", en Piero Boitani (cd.), Chaucer and the Italian Trecento, Cambridge, Londres, N. York: Cambridge University Press, 1984, pp. 231-248.

Marcus, Millicent, An Allegory of Form. Saratoga, California: Anma Libri, 1979.

Mazzota, Giuseppe. "The Decameron: The Marginality of Literature", University of Toronto Quarterly, 42 ( 1972). pp. 64-81.

Mrrmier. Guy, "A propos du Decaméron et de ses imitations: comme quoi le processus du dévoilement est indissociable de la structure de la nouvelle, de son style et de ses thèmes", Fifteen Century Studies, 4 (1981), pp. 131-155.

PABST, Walter. La novela corta en la teoría y en la creación literaria. Madrid, Gredos, 1972.

PARs. Gaston. "La nouvelle francaise aux xvè et xviè sièclès", en Joumal des Savants, mayo y junio de 1895, pp. 289-303, 342361. También en Melanges de Littérature Française du Moyen Age, publicadas por M. Roques, París: Champion, 1912, pp. 627 667.

Petrarca, Griseldis, cuento tr. del latín al francés por Victor Develay. Paris, Librairie des Bibliophiles, 1872.

Prologue du Miroir des Dames Mariées (Espejo de las damas casadas ], La Noble Marquise de Saluce, fol. $165^{\circ}$, en GolenistcheffKoutouzoff, L'Historie, p. 154.

Rasmissen, Jens, La Prose narrative française du xvè siècle. Copenhague: Ejnar Munksgaard, 1958.

Ri:Y-FLAUD, Bernadette. La farce ou la machine d rire. Genova: Droz, 1984.

Rossı, Luciano. "David Aubert autore della Cent Nouvelles nouvelles? I. La genesi della novella francese e l'attività lettcraria 
alle corte borgognone nel Quattrocento", Cultura Neolatina, 36 (1976), pp. 96-118.

_- "Per it testo delle Cent Nouvelles nouvelles: Ia centesima novella e il raconti dell'acteur", Medioevo Romanzo, VIII, (19811983), pp. 401-418.

SODERHeLM, Werner, La nouvelle française au xvè siècle. Paris: $\mathrm{H}$. Champion, 1910.

So7:ı, Lionello (ed.), La nouvelle française à la Renaissance, trabajos presentados por V. L. Saulnier. Génova-Paris: Slatkine, 1981.

_., "La Nouvelle française au xvè siècle", ponencia para el XXII Congreso de la Association Internationale des Études Françaises en julio de 1970, pub. en Cahiers de l'Association Internationale des Études Françaises, 23 (1971), pp. 67-84. Discusión. pp. $337-$ 342.

SriccA, Sandro, "Boccaccio and the Birth of the French Nouvelle", Forum lialicum, 11 (1977), pp. 218-247.

Touvo, Prieto. Contributo allo studio della novella francese del $x v e$ xv secolo considerata specialmente nella sua attinenze con la letteratura italiana. Roma: E. Loescher, 1895.

WeTZEı, Hermann, "Eléments Socio-historiques d'un genre Littéraire: L'Histoire de la Nouvelle jusqu'à Ccrvantes", en Sozzi (ed.), La nouvelle française a la Renaissance. Trabajos presentados por V. L. Saulnier. Ginebra-Paris: Slatkinc, 1981, pp. 41-78. 